\title{
Role of Kansei Experience for the Active Use of ICT among the Elderly
}

\author{
Ayako HASHIZUME* and Masaaki KUROSU** \\ * Faculty of System Design, Tokyo Metropolitan University, 6-6 Asahigaoka, Hino, Tokyo 191-0065, Japan \\ ** Center for ICT and Distance Education, The Open University of Japan, 2-11 Wakaba, Mihama, Chiba-shi, Chiba 261-8586, Japan
}

\begin{abstract}
Technological advances in recent years have brought us drastic changes in our daily life. ICT devices providing us the new technology have begun to be used for various goal-achievements in various situations. But there still exists a gap between high end users and low end users depending on their demographic traits, where one of the important traits is the generation or the age group. Authors conducted a field survey adopting the contextual inquiry method and analyzed the data by applying M-GTA, then summarized the information as a category relationship diagram. In the diagram, such factors as the motivation for using mobile phone, the active involvement to the communication and the mobile phone literacy were regarded as three principal components.
\end{abstract}

Keywords: User Experience, Elderly people, Information and Communication Technology (ICT), Qualitative approach, M-GTA

\section{INTRODUCTION}

With the progress and the diffusion of the ICT (Information and Communication Technology), many devices, such as PCs and mobile phones, have become more convenient and to be used in various scenes of our life. At the same time, in Japan, the progress of aging is very rapid and since 2005 Japan has become the most aged society in the world. Japan's percentage of elderly persons (percentage of total population aged 65 and over) shot up from $5 \%$ in $1950,7 \%$ in 1970 , and $10 \%$ in 1985 , to $23.1 \%$ in 2010 , and is expected to rise to $30.5 \%$ in 2025 and $40.5 \%$ in 2050 [1]. Because of these factors, Japanese manufacturers in electronics have developed the cell phones and PCs for elderly users [2,3], but there still exists a gap between high end users and low end users depending on the demographic traits. One of the marked differences is related to the difference among the age group. Whereas the progress of ICT is smoothly going upward recently, it was found that the elderly people are low in their usage rate of internet, for example, compared to young thru middle-aged people as shown in Fig. 1. According to Ministry of Internal Affairs and Communications, only about $70 \%$ of people of their late 60's and about $40 \%$ of their 70's are using ICT devices such as PCs and cell phones, although more than $90 \%$ of people of their 20's through 40's are using it [4]. In other words, senior people do not use the ICTs actively compared to young people.
Ownership ratio of mobile phones

Ownership ratio of PCs

\section{$(\%)$ \\ Internet utilization rate with ICT devices}

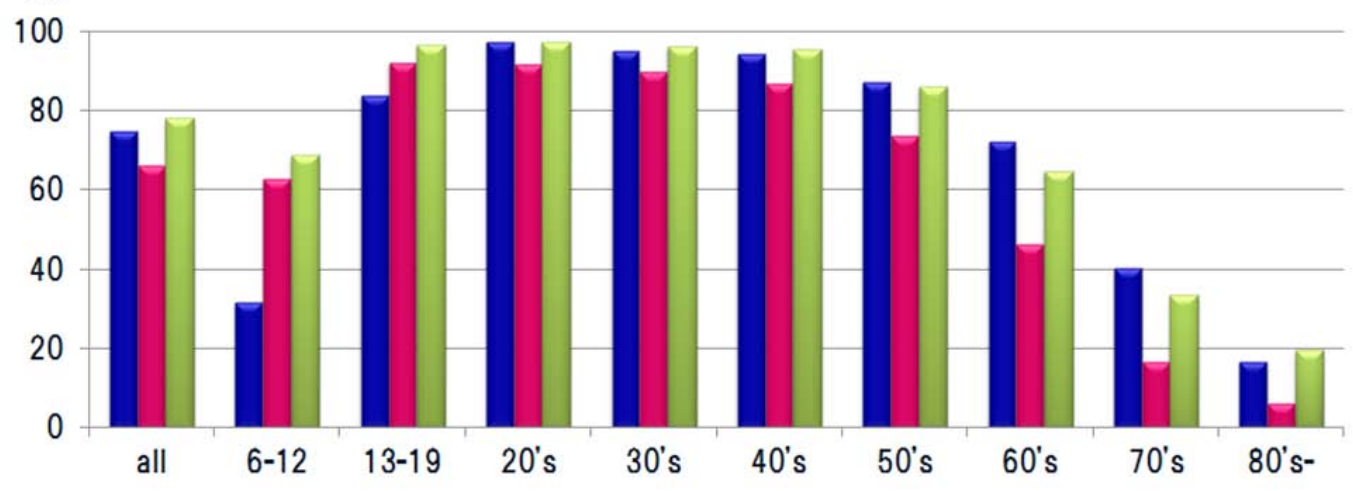

Figure 1: Usage ratio of ICT for each age group in Japan (2010). 
In our previous studies [5,6], we conducted a questionnaire survey based on the quantitative approach to grasp the overall trend of using the ICT devices. Answers to the questions showed some differences, such that elderly people are using less functions of ICT devices and they cannot operate functions that are widely known and used. Compared to young people, elderly people do not use the ICT devices actively. It was found that the elderly people do not use many functions of the cell phone effectively. It was also found that there is a generation gap between the elderly people and the young people regarding the use of the cell phone. This study focuses on the reason of such differences in relation to the value criteria among those people, in other words, how the design (appearance) and the usability are affecting the purchase of the cell phone by adopting the research result. In our other previous research [7], it was found that there are differences in the relative importance of the value criteria depending on age and gender, and the elderly people are not simply neglecting the design of devices (Kansei aspect) but are putting more emphasis on the ease of use (usability) and that they will regard the design as important if there are no usability problems.
Based on the conceptual analysis, Fig. 2 was described showing how changes in society may affect the life of elderly people. Because the lack of communication and the lack of information seemed to be two of the key factors in the negative aspects in the everyday life of elderly people, authors decided to focus on how they can become able to use ICT-related device and system, especially the mobile phone with an expectation that the facilitation of such device and system may decrease the negative aspects in their life.

As for the research method, authors adopted the qualitative approach using the contextual inquiry method [8].

\section{METHOD}

\subsection{Survey Method.}

The result of the questionnaire showed there is a difference in the literacy for ICT devices depending on the age, but it was not clear why and how there is such a difference between two age groups, i.e. 20's (younger generation) and 60-70's (older generation). So we conducted the interview research to identify the reasons. We adopted the contextual inquiry method and conducted

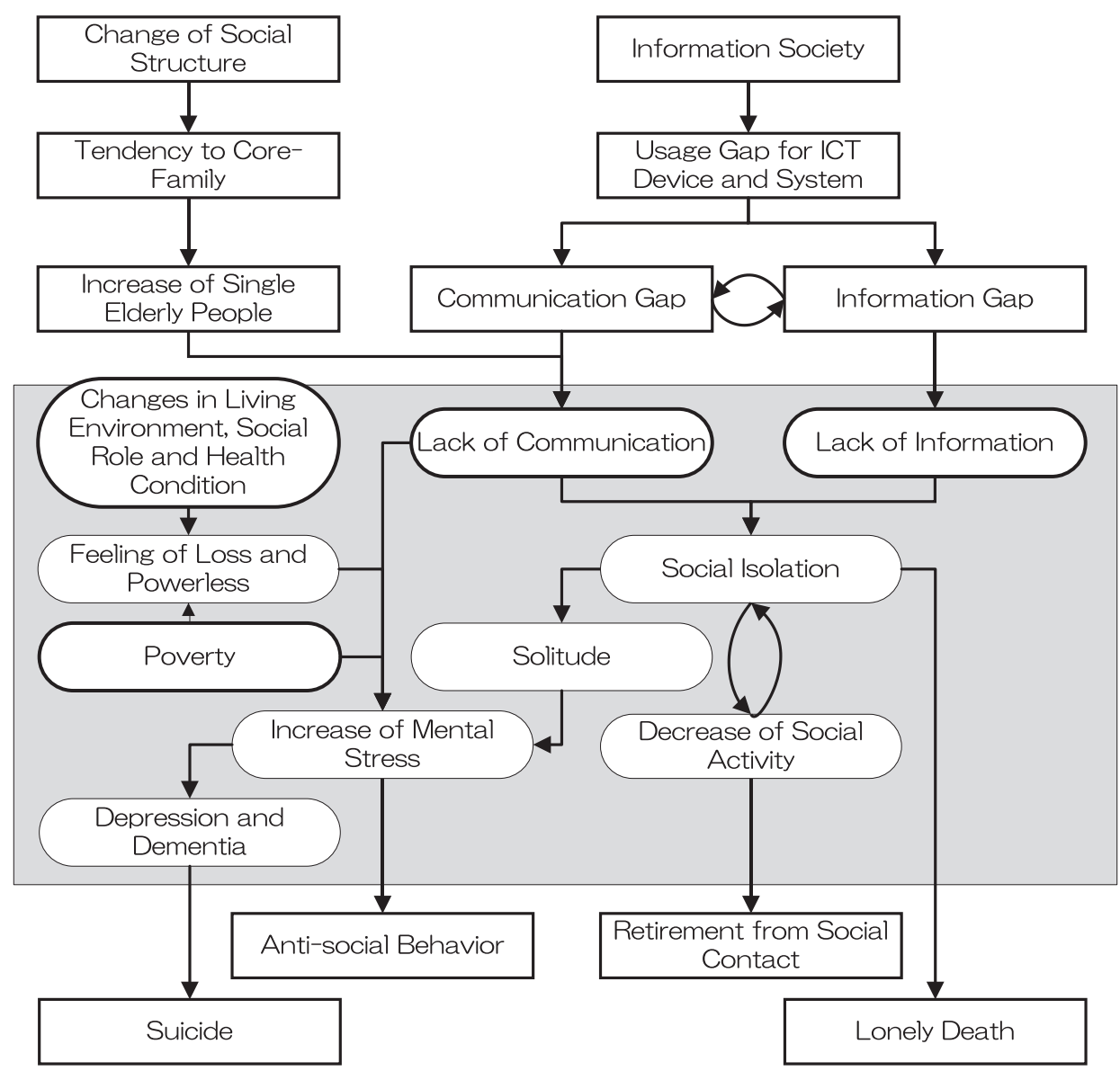

Figure 2: Changes in society and the life of elderly people. 
interviews at informants' residential area (home or nearby places).

Regarding the definition of the elderly people, we defined them as those who are over 60, whereas WHO (World Health Organization) defines them as those over 65. It is because the elderly people usually retire from their job at around 60 and their life environment changes drastically after the retirement.

We visited the house of informants and spent total of 4 hours including 2 sessions for 2 hours. Informants were 36 in total including 16 young people and 20 elderly people (Table 1), half of whom were living in the urban area and the rest were living in the rural area with equal number for male and female.

\subsection{Instruction and Questions.}

First we explained about the research that it is for the academic purpose and does not have anything with the sales activity. Then we explained about the expected time of the research, about the free stance of the informant that they can refuse to answer to any questions of which the informant may feel unpleasant, about our treatment of the individual information, and about the purpose of audio recording. After obtaining their consent, we started the interview.

Next, we asked about the rough information on the use of the cell phone and the individual information (life history, current life, social relationship, family membership, etc.) as the background information. Research questions of the interview were as follows. Because we adopted the semi-structured interview technique, the order of topics varied from session to session and some other questions were added.

$<$ About the informant $>$

- Life history,

- Their daily job,

- Avocation,

- Value attitude,

- Their view on their own quality of life,

- Their personal relationship with friends and other people,

- Family membership....etc.

Table 1: Informants

\begin{tabular}{|r|c|c|}
\hline Generation & 20 's & 60-70's \\
\hline Male & 8 & $10(2)$ \\
\hline Female & 8 & $10(2)$ \\
\hline Total & 16 & $\mathbf{2 0}(\mathbf{4})$ \\
\hline Average age & 25.25 & 69.26 \\
\hline
\end{tabular}

※The numbers in parenthesis are ICT have-nots.
$<$ About the use of the cell phone $>$

- History of use,

- Actual use,

- Functions that they use,

- Differentiation of the use among various functions and other devices,

- Contexts and situations of the use of the cell phone,

- How would they do when they face with problems while using the cell phone.

\subsection{Analysis}

For the interview data, we depicted a number of fragmental information affecting to the use of ICT using the Modified Grounded Theory Approach (M-GTA), that is one of the qualitative analysis method, proposed by Kinoshita $[9,10]$. It is based on the Grounded Theory Approach (GTA) originally proposed by Glaser and Strauss [11]. We conducted an analysis of all transcripts of the conversation in the interview using the M-GTA as the following processes (Fig. 3, Fig. 4, and Fig. 5), and the results showed some differences in the

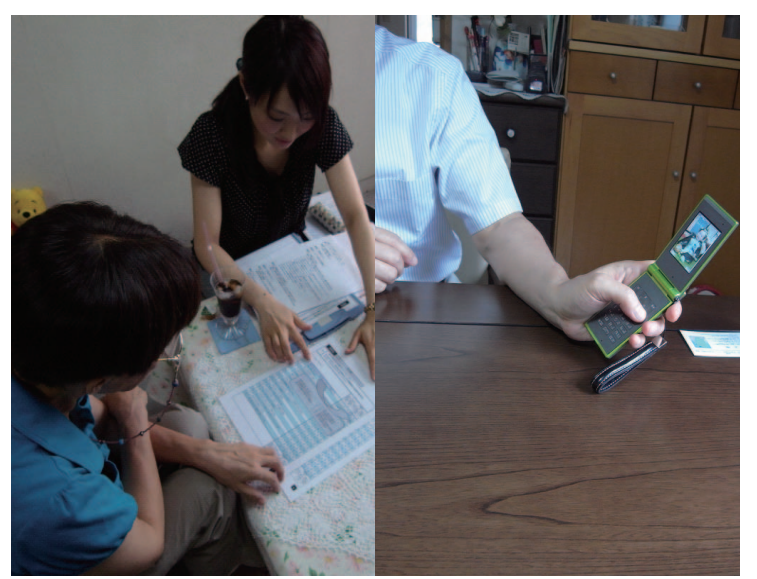

Figure 3: Interviewing Informants at their house.
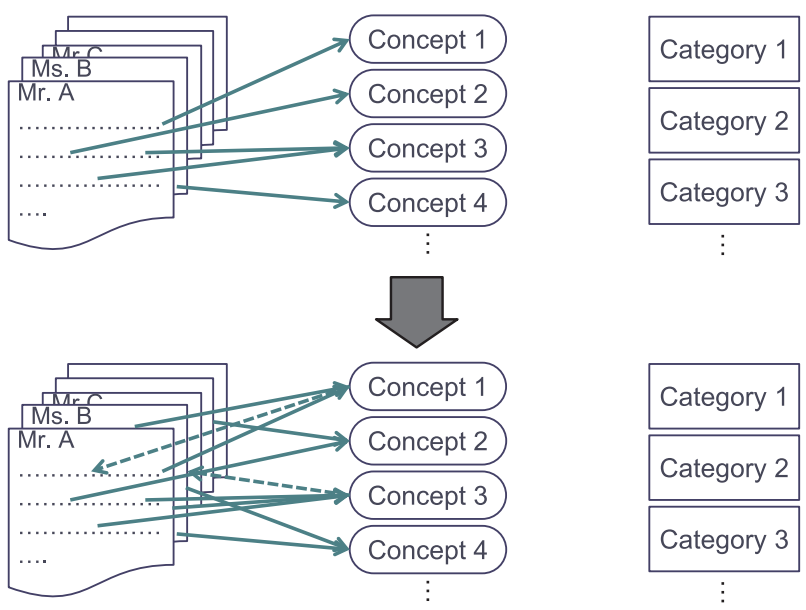

Figure 4: Analytical Procedure by M-GTA: STEP 1 
use of the ICT devices between young people and elderly people.

$<$ The M-GTA Processes>

STEP 1: We produced concepts from the verbatim reports of each participant, using specific examples. Then, clarified the concepts through concepts correction and the integration (Fig. 4).

STEP 2: We went through the concepts by reexamining the definitions and the names of concepts. We then refined and extracted the eventual concepts (Fig. 5).

STEP 3: Then, we produced and extracted categories and grouped the concepts into different categories, and showed the relationships between them as the association chart (Fig. 6).
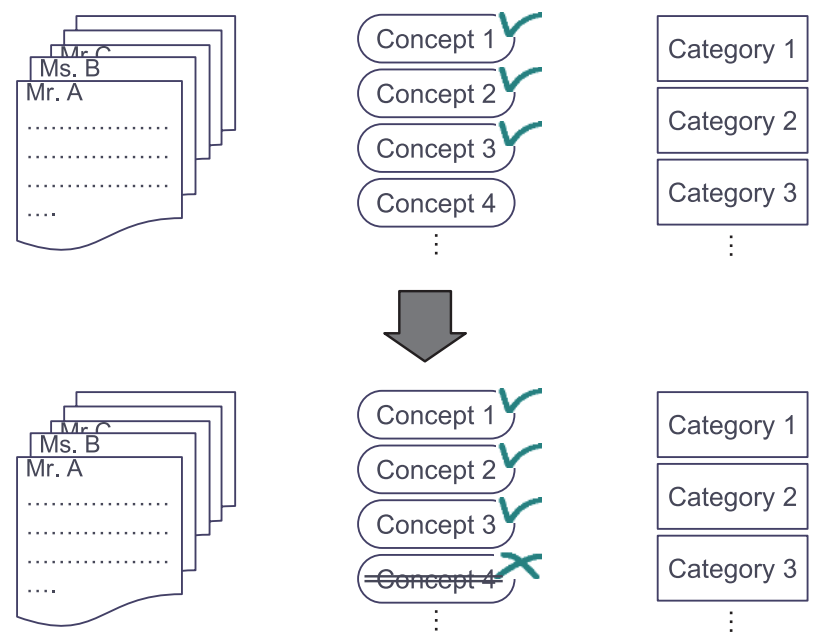

Figure 5: Analytical Procedure by M-GTA: STEP 2
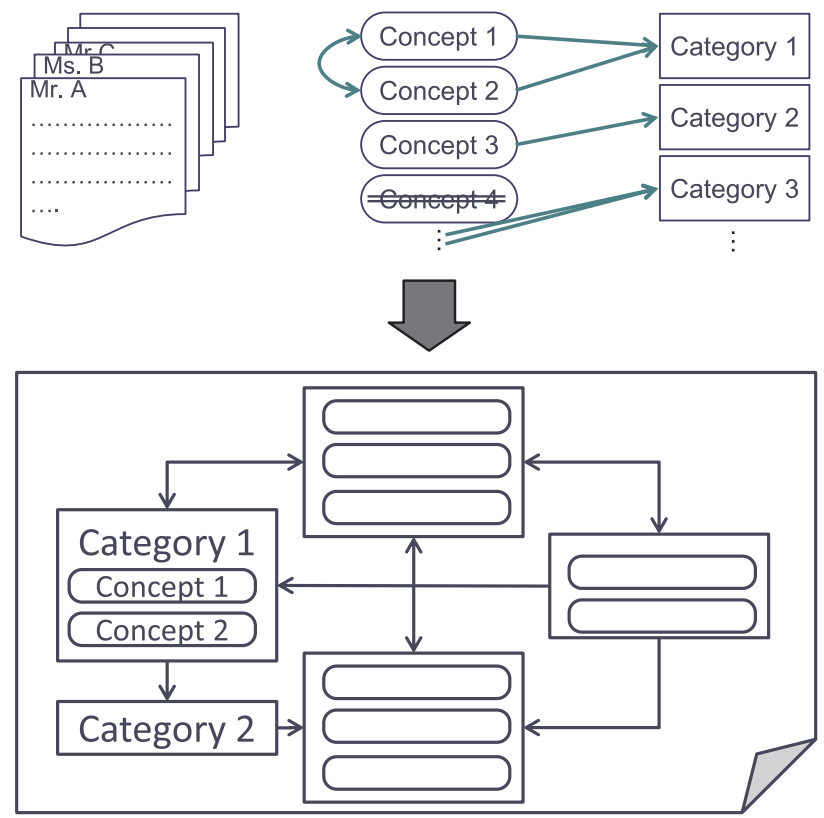

Figure 6: Analytical Procedure by M-GTA: STEP 3

\section{RESULT}

The interview data was first transcribed and then analyzed by M-GTA using MAX-QDA software. In the result of the M-GTA analysis, we produced and extracted concepts and finally we found 21 concepts from the data of elderly people, and put them into 8 categories (Table 2). In the same way, we took with the youth concepts, putting 17 concepts into 7 categories (Table 3). Then, we drew the category relationship diagram as shown in Fig. 7.

Among them, there was a category "Emotional aspects of ICT usage" that was affected by the category "Experience using ICT" and affected to the categories "Motivation for the use of ICT" and "Active attitude to communication" In other words, a positive emotional experience played a key role for the active use of the ICT devices. Furthermore, the category "Emotional aspects of ICT usage" included concepts of Kansei experiences, such as "Happiness and security experienced through usage" and "Realizing how convenient ICTs are" that can be classified as the positive Kansei experiences, and another concept "Troubles during usage" is a negative one.

A strategy was thought to be effective that aims to increase the level of literacy after having increased the motivation to use the cellphone. It is especially important that the user experience (UX) of the ICT devices with positive emotions were based on the "Kansei experience" for elderly people. Therefore, it is important to increase the positive Kansei experience for the active use of the ICT devices among elderly people, and it will lead to a higher level of the ICT literacy.

\section{CONCLUSIONS}

Findings based on the data analysis are as follows:

1. In order to increase the ICT literacy among the elderly people, the motivation and the real experience of usage are quite important.

2. If an adequate social support is given to the elderly people and the problem they may be facing could be solved, the ICT literacy will be increased.

3. Factors that facilitate the motivation for the use of ICT include the active attitude to the communication and the positive Kansei (hedonic) experience during the usage.

4. On the contrary, factors that demoralized the use of ICT include the change of life environment due to the retirement, the decrease of necessity of use of the ICT, the decrease of motivation to the active 
Table 2: Concepts and Categories with Elderly.

\begin{tabular}{|c|c|c|}
\hline Eventual Extracted Concepts & \multicolumn{2}{|r|}{ Categories } \\
\hline Active Att itude to Communication & A & Active Attitude to Communication \\
\hline Width of Social Relationship & \multirow{2}{*}{ B } & \multirow{2}{*}{ Fulfillment of Social Relationship } \\
\hline Depth of Social Relationship & & \\
\hline Financial Problem & \multirow{4}{*}{ C } & \multirow{4}{*}{ Change in Living Environments and minds } \\
\hline Need for ICT & & \\
\hline Self-consciousness of Aging & & \\
\hline Retirement & & \\
\hline Opportunity of Social Support & \multirow{2}{*}{$\mathrm{D}$} & \multirow{2}{*}{ Social Support for the Use of ICT } \\
\hline Active Use of Social Support & & \\
\hline Ability to Collect Relevant Information & \multirow{3}{*}{$E$} & \multirow{3}{*}{ ICT Literacy } \\
\hline Knowledge of ICT & & \\
\hline Problem Solving Ability & & \\
\hline Active Use & \multirow{3}{*}{$\mathrm{F}$} & \multirow{3}{*}{ Motivation for the Use of ICT } \\
\hline Resignation of Use & & \\
\hline Interest in ICT & & \\
\hline Frequency of Use & \multirow{3}{*}{ G } & \multirow{3}{*}{ Experience Using ICT } \\
\hline Length of Use & & \\
\hline Problem Solving Ability & & \\
\hline Realizing how Convenient ICT are & \multirow{3}{*}{$\mathrm{H}$} & \multirow{3}{*}{ Emotional Aspects of ICT Usage } \\
\hline Happiness \& Security Experienced through Usage & & \\
\hline Troubles during Usage & & \\
\hline
\end{tabular}

Table 3: Concepts and Categories with Youth.

\begin{tabular}{|c|c|c|}
\hline Eventual Extracted Concepts & \multicolumn{2}{|r|}{ Categories } \\
\hline Active Att itude to Communication & A & Active Attitude to Communication \\
\hline Width of Social Relationship & \multirow{2}{*}{ B } & \multirow{2}{*}{ Fulfillment of Social Relationship } \\
\hline Depth of Social Relationship & & \\
\hline Financial Problem & \multirow{3}{*}{ C } & \multirow{3}{*}{ Change in Living Environments and minds } \\
\hline Need for ICT & & \\
\hline Awareness about the Effective Use of Time & & \\
\hline Ability to Collect Relevant Information & \multirow{3}{*}{$E$} & \multirow{3}{*}{ ICT Literacy } \\
\hline Knowledge of ICT & & \\
\hline Problem Solving Ability & & \\
\hline Active Use & \multirow{2}{*}{$\mathrm{F}$} & \multirow{2}{*}{ Motivation for the Use of ICT } \\
\hline Interest in ICT & & \\
\hline Frequency of Use & \multirow{3}{*}{ G } & \multirow{3}{*}{ Experience Using ICT } \\
\hline Length of Use & & \\
\hline Problem Solving Ability & & \\
\hline Realizing how Convenient ICT are & \multirow{3}{*}{$\mathrm{H}$} & \multirow{3}{*}{ Emotional Aspects of ICT Usage } \\
\hline Happiness \& Security Experienced through Usage & & \\
\hline Troubles during Usage & & \\
\hline
\end{tabular}

communication due to the self-consciousness of the aging, etc.

5. But if the retirement may be regarded positively as the attainment of freedom, the elderly people are expected to have the active motivation. And because they may have more free time than when they were working, the interest to the ICT can be increased.

6. Furthermore, changes in the life situation and the life consciousness will positively influence the social relationship in general. This fulfillment of the social relationship is related to the existence of the opportunity to get the social support and the acceptance of such support.
From the result of this study, it could be said that the improvement of the usability of devices is quite important especially for the elderly users. But because there are individual differences regarding the literacy to use the ICT among the elderly people, the user interface of the ICT devices should be optimal for both levels of people. In addition to the deliberate consideration on the usability, the design or the Kansei (hedonic) aspect should also be considered based on the fact that the elderly people are not simply denying the Kansei aspect. In Japan, many ICT devices have been developed that target the elderly people with the intention that the use of the cell phone will be increased effectively and effi- 


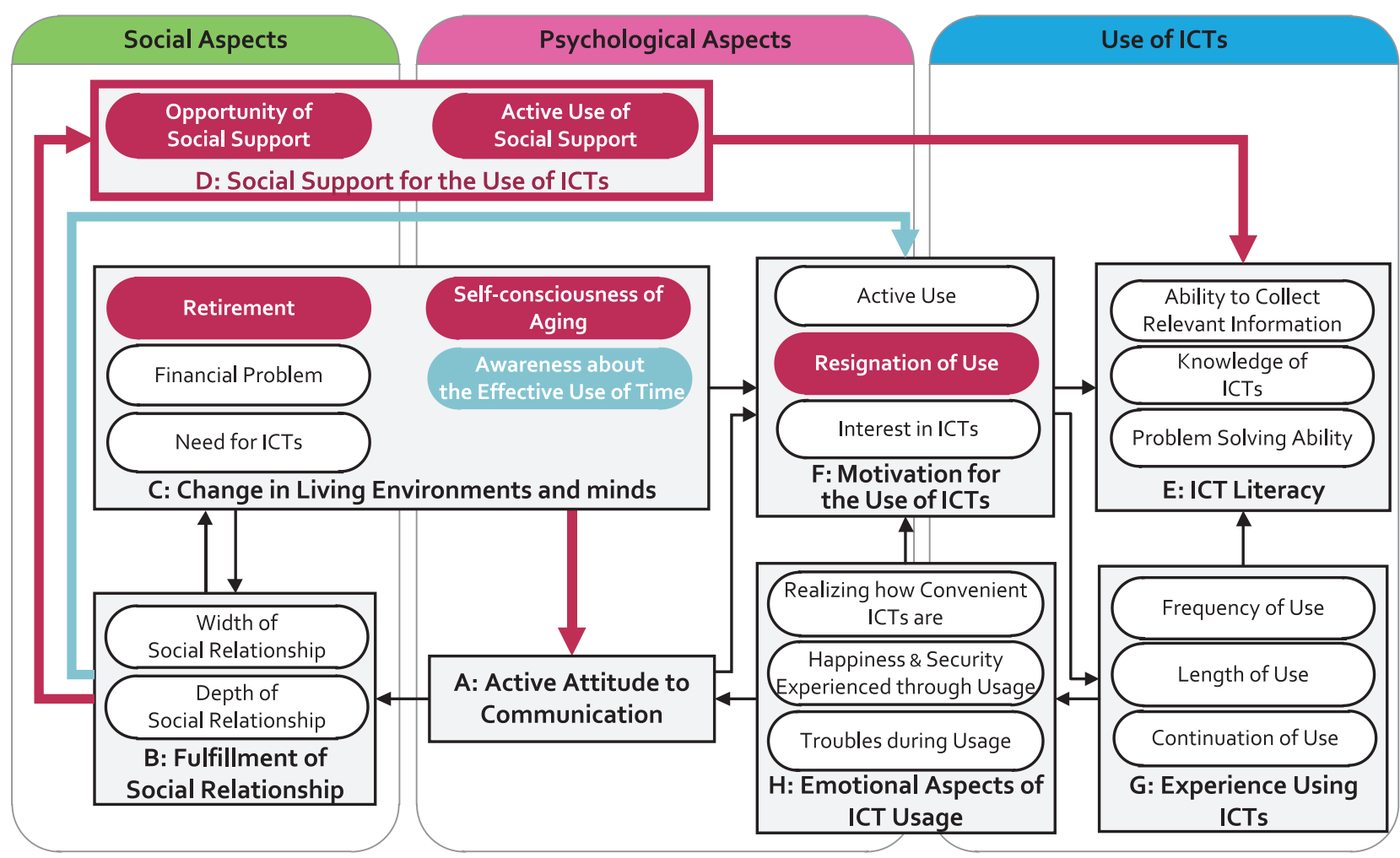

: Categories and relations that fall into the group of elderly only
: Categories and relations that fall into the group of youth only
: Categories and relations that fall into both age groups

Figure 7: Category Relationship Diagram.

ciently. These devices were developed considering the physical characteristics of the elderly people, but the usability as a whole has not yet fully been optimized in such devices.

It was found that it is difficult to answer to "why" questions by just applying the quantitative method such as the questionnaire. By applying the qualitative approach such as the contextual inquiry, it is possible to understand the situational structure of the user and their context of use and to give a better understanding to the result of the quantitative approach. This approach will surely give the insight to the total design of the high-tech device such as the cell phone.

\section{ACKNOWLEDGEMENTS}

Authors would like to express our sincere delight to Japan Society for the Promotion of Science (JSPS). This work was supported by Grant-in-Aid for JSPS Fellows from JSPS.

\section{REFERENCES}

1. Cabinet Office Japan, Annual Report on the Aging Society, 2011.

2. Irie R., et al.; The Challenge to the Universal Design in the Development of the Cell Phone "Easy Phone (Raku-Raku Phone)”, FUJITSU, 56(2), 2005, (in Japanese)

3. http://www.fmworld.net/fmv/rakuraku/

4. Ministry of Public Management, Home Affairs, Posts and Telecommunications "A Report on the Use of Communication System in 2009", 2010.

5. Hashizume A., Kurosu M., Kaneko T.; Use of Cell Phone by Senior Users Compared to Young Users, The 12th World Multi-Conference on Systemics, Cybernetics and Informatics Proceedings, Florida, USA, 2008, pp.244-247, (in English).

6. Hashizume A., Kurosu M., Kaneko T.; The Choice of Communication Media and the Use of Mobile Phone among Senior Users and Young Users: Computer-Human Interaction, Springer-Verlag Berlin Heidelberg, pp.427-436, 2008.

7. Hashizume A., Kurosu M.; Real user experience of 
ICT devices among elderly people, Human Centered design, Springer-Verlag Berlin Heidelberg, pp.227234, 2011.

8. Beyer H., Holtzblatt K.; Contextual Design: Defining Customer-Centered Systems, Morgan Kaufmann, 1998.

9. Kinoshita Y.; M-GTA Grounded Theory Approach: Reproduction of a Qualitative Experimental Study, Kobundo Publishers Inc., 1999.

10. Kinoshita Y.; M-GTA Grounded Theory Approach: Invitation for Qualitative Research, Kobundo Publishers Inc. 2003.

11. Glaser B. G., and Strauss A. L.; The discovery of grounded theory, Aldine de Gruyter, 1967.

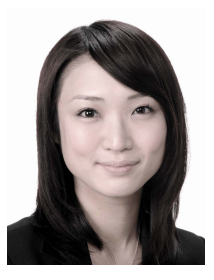

\section{Ayako HASHIZUME}

Ayako Hashizume received the Ph.D. in Kansei Science from Tsukuba University, Japan, in 2011. Her research interests include psychology of emotion and Kansei, engineering in relation to HCD (Human Centered Design) and UX (User Experience), especially among elderly users. She was awarded the Kids Design Prospective Competition 2008 from the Japan Kids Design Association and the Best Design Prize at the Design Marathon 2009 from IAUD from the International Association for Universal Design.

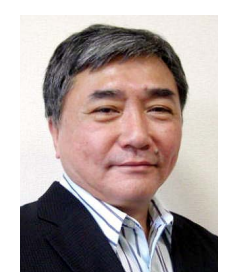

\section{Masaaki KUROSU}

Masaaki Kurosu is a professor at the Open University of Japan, since 2009. He is also a professor at the Graduate University for Advanced Studies as well as a President of HCD-Net (Human Centered Design Network). Based on his career as a usability professional in industry and academia, he proposed a concept of user engineering and is now proposing an ADA (Artifact Development Analysis) and a new concept of UX (User Experience). He is a member of IFIP/TC13, and ISO TC159/SC4/WG6. He is also a member of ACM SIGCHI, Usability Professionals' Association, IEEE Computer Society, Human Interface Society (Japan), Japanese Psychological Association, Japan Ergonomics Society, and Japanese Society for the Science of Design. 